adequacy of excision was better and the implications of an incompletely excised basal cell carcinoma are usually not as serious. Nevertheless, it is clear from our results that attention to pathology reports is critical as some tumours where recurrence is expected do not appear to have had further treatment. The follow up data on malignancies adds support to the view that adequate record keeping is a valid criterion to include in assessment of premises for minor surgery; this was the single most frequent reason for failure to meet criteria for adequacy of premises in a recent study. ${ }^{9}$

We conclude that minor surgery in general practice has advantages but also raises concern about the increase in laboratory workload, the likelihood that some benign lesions may be excised for no reason other than diagnostic uncertainty, the inappropriateness of biopsy of rashes, and the generally poor rate of diagnosis and adequate treatment of malignant tumours. Our results highlight the relatively small number of specimens submitted by even the most prolific general practitioners, and suggest that further training and guidelines may be helpful.

1 Department of Health and Welsh Office. General practice in the National Health Service: a new contract. London: Department of Health and W'elsh Office, 1989.

2 Brown JS. Minor operations in general practice. BMF 1979;i:1609-10.

3 Godfrey $\mathrm{E}$, Watkiss $M$, Schneiden $\mathrm{H}$. Initiation and evaluation of a pilo scheme for minor surgery in general practice. Health Trends 1990;22:57-9.

4 Sharman J. Patient's response to a general practice minor surgery service. Practitioner 1986;230:27-9.

5 Shrank AB. Correspondence. Health Trends 1990;22:181.

6 Slater DN. Screening and the 1990 contract. BMF 1991;300:1074.

7 Pringle M, Hasler J, De Marco P. Training for minor surgery in general practice during preregistration surgical posts. BMf 1991;302:830-2

8 Richards T. Competence for GP surgery. BMF 1991; 301:307-8.

9 Zoltie N, Hoult G. Adequacy of general practitioners' premises for minor Zoltie N, Hoult G. Adequacy of

10 Morgan DR, Lamont TJ, Dawson JD, Booth C. Decontamination of instruments and control of cross infection in general practice. $B M 7$ 1991;300:1379-80.

11 Dando P. Medico-legal aspects of minor surgery. Fournal of the Medical Defence Union 1991:1:12-3.

12. Hunt AC, Sherwood A. Competence for GP surgery. BM 1991;301:495

13 Pitcher R, Gould DJ, Bowers DW. An analysis of the effects of general practice minor surgery clinics on the workload of a district general hospital pathology and dermatology department. Brf Dermatol 1991:125(suppl 38):93.

14 Stern RS, Boudreux C, Arndt KA. Diagnostic accuracy and appropriateness of care for seborrheic keratoses. A pilot study of an approach to quality assurance for cutaneous surgery. FAMA 1991;265:74-7.

15 Nixon RDL, Dorevitch AP, Marks R. Squamous cell carcinoma of the skin accuracy of clinical diagnosis and outcome on follow-up in Australia. Med F A ust 1986;144:235-9.

(Accepted 9 October 1991)

\section{Appendix}

(1) Correct diagnosis-Accurate diagnoses were recorded; "mole" was taken to mean naevus.

(2) Incorrect diagnosis-Cases where (a) clinical information was omitted entirely or was brief and uninformative (such as "lump"), (b) the clinical diagnosis suggested was inconceivable given the pathological diagnosis (such as diagnosis of lipoma as a wart), or (c) the diagnosis was potentially dangerous - for example, "mole" for squamous cell carcinoma.

(3) Uncertain-For example, the clinical information for most rashes biopsied did not enable the accuracy of diagnosis to be established.

(4) Adequate description-For example, keratosis was used for a wide variety of different diagnoses and as a descriptive term, so was coded as a description unless qualified by a more specific term such as actinic (solar) keratosis, etc.

(5) Reasonable suggested diagnosis-Almost all pathological diagnoses where the clinical diagnosis was not accurate but suggested "mole" or "wart" were classified as category 5 unless the suggestion was entirely inappropriate. For analysis of tumours, we specifically recorded whether descriptions or suggested diagnoses included the possibility of any malignant disorder.

\title{
Diagnostic value of microtympanometry in primary care
}

\author{
Ruut A de Melker
}

\section{Abstract}

Objective-To determine the reliability, validity, and feasibility of a new hand held microtympanometer.

Design-Comparison of microtympanometry by two independent observations of a general practitioner and a nurse, and against a validated reference instrument.

Setting-Primary care health centre of a school for the deaf in the United States.

Subjects-111 schoolchildren receiving a regular check up.

Main outcome measures-Tympanometry with the Grason Stadler 28, classified with a slightly modified Jerger's classification.

Results-Interobserver reliability was $\mathbf{0 . 9 5}$ (Cohen's $x$ ). Results of microtympanometry were highly comparable with results of the reference instrument (likelihood ratio of positive results, 161·2).

Conclusions - The microtympanometer could be used in general practice: it is hand held, child friendly, easy to handle, and accurate.

Department of General Practice, University of Utrecht, 3511 ZC Utrecht, Netherlands

Ruut A de Melker, MD, professor

BMF 1992;304:96-8

\section{Introduction}

Tympanometry is a reliable and sensitive test for diagnosing otitis media with effusion in children, ${ }^{1-3}$ which is difficult to diagnose in general practice ${ }^{+6}$ : data collected by history is of limited value ${ }^{78}$ and otoscopy is rather unreliable. ${ }^{14910}$ The cumulative incidence of bilateral otitis media with effusion is $50-60 \%$ in open populations of children aged 2-6 years. ${ }^{6-811}$ About 5\% of 5 year olds have severe otitis media with effusion and suffer developmentally as a result. ${ }^{12-14}$

The hand held microtympanometer (Welch Allyn, Skaneateles Falls, New York) seems a good instrument to diagnose otitis media with effusion in primary care, but has not been sufficiently validated. ${ }^{15}$ The aim of this study is to determine the reliability, validity, and feasibility of using the microtympanometer. I set out to determine the interobserver and intraobserver reliability of microtympanometry in a group of schoolchildren aged 1-16 years; to discover the likelihood ratio of positive and negative results of the microtympanometer with the Grason Stadler GSI 28 tympanometer as reference instrument; and to assess the feasibility of a general practitioner and a nurse trained in ear, nose, and throat practice using the microtympanometer in a primary care setting.

\section{Subjects and methods}

The population consisted of 111 schoolchildren aged 1-16 years in a school for the deaf. They came for a regular ear, nose, and throat checkup in the primary care health centre of the school during the period November 1989 to January 1990. Primary health care was delivered by two nurses, a family doctor, and a ear, nose, and throat surgeon as consultant.

The history of upper respiratory tract infections was 
collected from the records of the health centre of the school. Pneumatic otoscopy was carried out by a nurse trained in ear, nose, and throat practice to judge for cerumen and the direction of the ear canal. Microtympanograms were made independently by the nurse and the author, an experienced general practitioner with special interest in this field. Tympanometry with the Grason Stadler 28 was carried out by the nurse. If necessary the ear was cleaned of cerumen. In 20 children the measurements were repeated after two weeks.

Tympanometry measures changes of acoustic admittance of a test zone in a closed ear canal as a function of changing air pressure. ${ }^{3}$ After otoscopy a test probe is placed on the ear canal. In the test probe there are three small holes: one for the test tone, one for the reflected noise, and one for the air pump. In this way the impedance and compliance of the eardrum under variable pressure on the eardrum is measured. The result of the measurement is printed as a tympanogram. The position of the compliance peak indicates the pressure in the middle ear; the height of the peak indicates the compliance of the eardrum ${ }^{3}$; the gradient indicates the shape of the curve in the vicinity of the peak. The microtympanometer is an acoustic admittance meter with a test tone of $226 \mathrm{Hertz}$ and a tympanometric peak pressure range of +200 to -300 $\mathrm{dPa}$. The reference instrument used, the Grason Stadler 28 Auto Tymp, has a test tone of $226 \mathrm{Hertz}$ and a peak pressure of +200 to $-400 \mathrm{dPa}$.

A slightly modified Jerger's classification of the tympanograms was used (box). ${ }^{7} \mathrm{~A}$ and $\mathrm{Cl}$ curves were defined as "normal, no effusion" because of the low predictive value of a $\mathrm{Cl}$ curve for effusion; and $\mathrm{B}$ and $\mathrm{C} 2$ curves were defined as "abnormal, effusion very probable" because of their high predictive value for effusion. ${ }^{23}$ The gradient of the curves printed on the microtympanograms were classified in four groups: 0 , $5-115,120-135$, and $\geqslant 140$. The cutoffs were based on the mean $(\mathrm{SD})$ values and frequencies of values.

The tympanograms were classified by the author. A sample of $25 \%$ of all tympanograms was classified by another well trained general practitioner. The interobserver reliability of these classifications was very high (Cohen's x 0.95).

Cohen's $x$ was used to determine the interobserver agreement between the microtympanograms read by the practice nurse and the general practitioner. Cohen's $x$ is an index of concordance characterised by correction for the chance agreement that would be expected to occur if two classifications were totally unrelated. ${ }^{17}$ It is appropriate for discrete variables. ${ }^{18}$ Sensitivity, specificity, and the likelihood ratios as an index for the diagnostic value of the microtympanometer were determined with the Grason Stadler 28 as reference instrument. The likelihood ratio contrasts the proportions of patients with and without otitis media with effusion who display the presence (or absence) of abnormal results of tympanometry. ${ }^{19}$

To determine the influence of age on the dichotomised results of tympanometry with the Grason Stadler 28 odds ratios with $95 \%$ confidence intervals were calculated. The odds ratio expresses the strength of the association of age and otitis media with effusion by comparing outcome rates in patients in different age categories. The higher the odds, the greater the association. ${ }^{1718}$ Confidence intervals indicate the precision of the sample study estimates as population values..$^{20}$

\section{Results}

With regard to intraobserver reliability, no relevant differences were found between the two measurements of the same 20 children with the microtympanometer

\section{Modified Jerger's classification}

Type A curve Maximum compliance same or more than middle ear pressure from -99 to $+200 \mathrm{dPa}$

Type $\mathrm{B}$ curve Maximum compliance $<0 \cdot 2$ or middle ear pressure $<400 \mathrm{dPa}$

Type $\mathrm{C} 1$ curve Maximum compliance same or $>0 \cdot 2$ with middle ear pressure of -199 to $-100 \mathrm{dPa}$

Type $\mathrm{C} 2$ curve Maximum compliance same or $>0 \cdot 2$ with middle ear pressure of -399 to $-200 \mathrm{dPa}$

by the general practitioner (table I). The interobserver reliability between the ear, nose, and throat nurse and the general practitioner was very high (table II). The interobserver agreement of the gradients printed on the two microtympanograms was low (table III).

TABLE I - Intraobserver reliability of microtympanometry by general practitioner; two week interval between measurements (20 children)

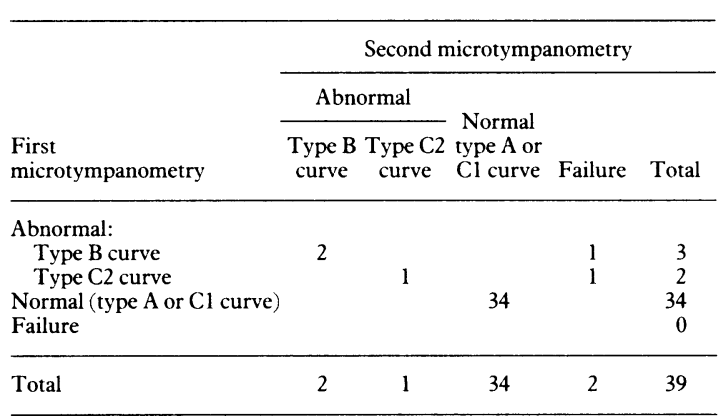

TABLE II-Interobserver reliability of microtympanometry of ear, nose, and throat nurse and general practitioner (111 children)

\begin{tabular}{|c|c|c|c|c|c|}
\hline \multirow[b]{3}{*}{$\begin{array}{l}\text { Microtympanometry by } \\
\text { general practitioner }\end{array}$} & \multicolumn{5}{|c|}{ Microtympanometry by nurse } \\
\hline & \multicolumn{2}{|c|}{ Abnormal } & \multirow{2}{*}{$\begin{array}{l}\text { Normal } \\
\text { type A or } \\
\text { Cl curve }\end{array}$} & \multirow[b]{2}{*}{ Failure } & \multirow[b]{2}{*}{ Total } \\
\hline & $\begin{array}{l}\text { Type B } \\
\text { curve }\end{array}$ & $\begin{array}{l}\text { Type C2 } \\
\text { curve }\end{array}$ & & & \\
\hline \multicolumn{6}{|l|}{ Abnormal: } \\
\hline Type B curve & 14 & & & & 14 \\
\hline Type C2 curve & 1 & 17 & 1 & & 19 \\
\hline Normal (type $\mathrm{A}$ or $\mathrm{Cl}$ curve) & & 2 & 171 & 1 & 174 \\
\hline Failure & & 1 & & 7 & 8 \\
\hline Total & 15 & 20 & 172 & 8 & 215 \\
\hline
\end{tabular}

Cohen's $x=0 \cdot 95$

TABLE III - Interobserver agreement of the gradient of microtympanograms assessed by ear, nose, and throat nurse and general practitioner (111 children)

\begin{tabular}{|c|c|c|c|c|c|}
\hline \multirow{3}{*}{$\begin{array}{l}\text { Gradient assessed } \\
\text { by general } \\
\text { practitioner }\end{array}$} & \multicolumn{5}{|c|}{ Gradient assessed by nurse } \\
\hline & \multicolumn{2}{|c|}{ Normal } & \multicolumn{2}{|c|}{ Abnormal } & \multirow[b]{2}{*}{ Tota } \\
\hline & 0 & $5-115$ & $120-135$ & $\geqslant 140$ & \\
\hline \multicolumn{6}{|l|}{ Normal } \\
\hline 0 & 46 & 8 & 1 & 2 & 57 \\
\hline $5-115$ & 8 & 109 & 18 & & 135 \\
\hline \multicolumn{6}{|l|}{ Abnormal: } \\
\hline 120-135 & 1 & 14 & 6 & 1 & 22 \\
\hline$\geqslant 140$ & 2 & 3 & & 3 & 8 \\
\hline Total & 57 & 134 & 25 & 6 & 222 \\
\hline
\end{tabular}

Cohen's $x=0 \cdot 25$.

The results of microtympanometry by the general practitioner were highly comparable with the results of the reference instrument, and the likelihood ratio of abnormal results of microtympanometry was very high (table IV). There were three failures with the microtympanometer and six with the reference instrument; all except one were in different ears. 
TABLE IV-Microtympanometry by general practitioner compared with tympanometry with Grason Stadler 28 (111 children)

\begin{tabular}{|c|c|c|c|c|c|c|}
\hline \multirow[b]{3}{*}{ Microtympanometry } & \multicolumn{5}{|c|}{ Tympanometry } & \multirow{3}{*}{$\begin{array}{l}\text { Likelihood } \\
\text { ratio }\end{array}$} \\
\hline & \multicolumn{2}{|c|}{ Abnormal } & \multirow{2}{*}{$\begin{array}{l}\text { Normal } \\
\text { type A or } \\
\text { Cl curve }\end{array}$} & \multirow[b]{2}{*}{ Failure } & \multirow[b]{2}{*}{ Total } & \\
\hline & B & $\mathrm{C} 2$ & & & & \\
\hline \multicolumn{7}{|l|}{ Abnormal } \\
\hline Type B curve & 12 & & & 4 & $16\}$ & $161 \cdot 2$ \\
\hline Type C2 curve & & 17 & 1 & 1 & $19\}$ & \\
\hline $\begin{array}{l}\text { Normal (type A or C1 } \\
\text { curve) }\end{array}$ & & 2 & 171 & & 173 & 0.065 \\
\hline Failure (repeated) & 2 & & & 1 & 3 & \\
\hline Total & 12 & 19 & 172 & 6 & 211 & \\
\hline
\end{tabular}

Sensitivity of abnormal curves $=29 / 31=0.94$

Specificity of normal curves $=171 / 172=0 \cdot 99$.

TABLE v-Number of abnormal and normal tympanograms, Grason Stadler 28 tympanometer by age category (105 children)

\begin{tabular}{lccccc}
\hline $\begin{array}{l}\text { Age } \\
\text { (years) }\end{array}$ & \multicolumn{2}{c}{ Abnormal } & & & $\begin{array}{c}\text { Unilateral } \\
\text { Odds ratio }\end{array}$ \\
\hline $1-5$ & 9 & 6 & 12 & 27 & $\begin{array}{c}9 \cdot 6 \\
(95 \% \text { confidence interval })\end{array}$ \\
$6-9$ & 2 & 4 & 32 & 38 & $\left.\begin{array}{c}(3 \cdot 42 \text { to } 26 \cdot 8) \\
0 \cdot 51\end{array}\right)$ \\
$\geqslant 10-16$ & 1 & 2 & 37 & 40 & $\begin{array}{c}(0 \cdot 18 \text { to } 1 \cdot 42) \\
0 \cdot 17\end{array}$ \\
$(0 \cdot 05$ to $0 \cdot 61)$
\end{tabular}

\begin{tabular}{lllll}
\hline Total & 12 & 12 & 81 & 105
\end{tabular}

Abnormal tympanograms were most common in the youngest age category, $1-5$ years (odds ratio $9 \cdot 6 ; 95 \%$ confidence interval $3 \cdot 42$ to $26 \cdot 8$; table V).

The microtympanometer was easy to handle and use with children. The general practitioner needs knowledge of and training in tympanometry and the use of the instrument. Otoscopy is necessary to look for cleanliness and the direction and width of the ear canal. If the test probe impacts on the wall of the ear canal, the microtympanometer signals failure and the test needs to be repeated. Especially for younger children it was sometimes difficult to find the right rubber tip for the test probe. It was absolutely necessary to close the ear canal appropriately. The procedure, otoscopy included, took only a few minutes.

\section{Discussion}

Tympanometry was carried out by an experienced ear, nose, and throat nurse; the measurements are valid and reliable. The Grason Stadler 28 is well validated and frequently used in the United States..$^{21} 22$ Jerger's classification is well accepted, especially in Europe. ${ }^{78}$ Our finding that age is an important predictive factor for abnormal tympanograms is in accordance with other studies. ${ }^{4} 1023$

Results with the instrument are comparable to those with the Grason Stadler 28. The high agreement between the two independent microtympanograms of the nurse and general practitioner shows that the microtympanometer is reliable. The hand held microtympanometer seems suitable for use in general practice and in well children's clinics.

The gradient printed on the microtympanogram seems not to be reliable. There is, however, no agreement regarding the usefulness of the gradient for predicting effusion. ${ }^{3}$

General practitioners need a training course with regard to the principles and procedure of tympanometry and the use of the microtympanometer, especially in the classification of tympanograms. Checks on intraobserver and interobserver reliability are necessary for appropriate classification. Microtympanometry has to be carried out in combination with otoscopy to prevent a failure due to the lumen of the test probe impacting on the wall of the auditory canal.

Microtympanometry may improve the general practitioner's ability to diagnose otitis media with effusion. With early detection and follow up in primary care an adequate referral policy for ear, nose, and throat surgery can be implemented. ${ }^{12}$ More validation studies are needed, especially in general practice and in hospital populations, using the "gold standard" of effusion or not after myringotomy.

I thank Dr Sylvan Stool, paediatric otolaryngologist, Children Hospital, Pittsburgh, and Rose Faber, ear, nose, and throat practice nurse, health centre of the School for the Deaf of Pennsylvania, Pittsburgh; Professor Francis TouwOtten, epidemiologist, for the statistical analysis; Dr Marijke Kuyvenhoven for her critical comment; and Welch Allyn for providing the microtympanometer.

1 Bluestone ChD, Cantekin EI. Design factors in the characterization and identification of otitis media and certain related conditions. Ann Otol Rhinol Laryngol 1979;88:13-27.

2 Cantekin EI, Bluestone ChD, Fria TJ, Stool SE, Beery QC. Identification of otitis media with effusion. Ann Otol Rhinol Laryngol 1980;89:190-5.

3 Bluestone $\mathrm{ChD}, \mathrm{Klein} \mathrm{JO}$. Otitis media in infants and children. Philadelphia W B Saunders, 1988.

4 Reves R, Budgett R, Miller D, Wadsworth J. Study of middle ear disease using tympanometry in general practice. $B M \mathcal{F}$ 1985;290:1953-6.

5 De Melker RA, Burke PD. Epidemiology of otitis media and the role of the general practitioner in management. Fam Pract 1988;5:307-13.

6 Van de Lisdonk EH, van den Bosch WJHM, Huygen FJA, Lagro-Janssen ALM. Ziekten in de huisartspraktijk [Morbidity in general practice]. Utrecht: Bunge, 1990.

7 Zielhuis GA, Heuvelmans-Heinen EW, Rach GH, van den Broek P. Environmental risk factors for otitis media with effusion in preschool children. Scand f Prim Health Care 1989;7:33-8.

8 Burke P. Otitis media with effusion in children: is medical management an option? f R Coll Gen Pract 1989;39:377-82.

9 Karma PH, Penttila MA, Sipila MM, Timonen MS. Diagnostic value of otoscopic signs in acute otitis media. In: Lim DJ, Bluestone ChD, Klein JO, Nelson JD, eds. Recent advances in otitis media. Proceedings of the fourt international symposium. Toronto: B C Decker, 1988.

10 Wilmot JF, Cable HR. Persistent effusion following acute otitis media tympanometry and pneumatic otoscopy. $\mathcal{F} R$ Coll Gen Pract 1988;38: $149-52$.

11 Casselbrant ML, Brostoff LM, Cantekin EI, Flaherty MR, Doyle WJ, Bluestone $\mathrm{ChD}$, et al. Otitis media with effusion in preschool children. Laryngoscope 1985;95:428-36.

12 Black NA, Sanderson CFB, Freeland AP, Vessey MP. A randomised controlled trial of surgery for glue ear. $B M F$ 1990;300:1551-6.

13 Otitis media with effusion in children [editorial]. Lancet 1990;336:23-4.

14 Chalmers D, Stewart I, Silva P, Mulena A. Otitis media with effusion in children the Dunedin study. Oxford: Blackwell; Philadelphia: Lippincott, 1989.

5 Margolis RH, Heller JW. Screening tympanometry criteria for medica referral. International foumal of Auditory Communication 1989;26:197-208.

16 Wazen JJ, Ferraro JA, Huges T. Clinical evaluation of a portable, cordles hand held ear analyzer. Ann Rhinol Laryngol 1988;97 (suppl 133):20-4.

17 Kelsey JL, Thompson WD, Evans AS. Methods in observational epidemiolog. New York, Oxford: Oxford University Press, 1986.

18 Feinstein AR. Clinical epidemiology: the architecture of clinical research. Philadelphia: W B Saunders, 1985.

19 Sackett DL, Haynes RB, Tugwell P. Clinical epidemiology: a basic science for clinical medicine. Boston: Little, Brown, 1985.

20 Gardner MJ, Altman DG. Statistics with confidence. London: BMJ, 1989.

21 Gates GA, Avery C, Cooper JC, Hearne EM, Holt GR. Predictive value of tympanometry in middle ear effusion. Ann Otol Rhinol Laryngol 1986;95: tympan.

22 Cantekin EI, Beery QC, Bluestone ChD. Tympanometric patterns found in middle ear effusions. Ann Otol Rhinol Laryngol 1977;86:16-20.

23 Zielhuis GA, Rach GH, van den Broek P. The occurrence of otitis media with effusion in Dutch preschool children. Otolaryngol 1990;15:147-53.

(Accepted 8 October 1991) 